RONEN ITSIK

\title{
ISRAEL'S DEFENCE ETHOS: MILITARY SERVICE AS A TURNING POINT
}

\section{INTRODUCTION}

The Jewish culture has a defining characteristic - since its creation it has been based on stories of survival and wars for salvation. Some of these stories became myths; hence, almost all of Israeli traditions are based on legends and real events that revolve around a never-ending war for survival. ${ }^{1}$ In recent years, it has been claimed that most Jewish citizens in Israel are trapped with a 'Siege Mentality', ${ }^{2}$ because of on-going wars against terror. The situation of being influenced by traditions that include myths and fighting actual wars leads to another claim, namely that the Israeli society is under the sway of a 'Defence Belief' - almost a kind of religion, whereby people believe that almost anything that surrounds them is an existential threat. ${ }^{3}$

Israel's army has been based on a citizen-soldier model since the establishment of the Israel Defence Forces (IDF) following the Independence War of 1948 . Hence, in the last 70 years the vast majority of Israelis have served in the army, as did their parents, thus it became traditional to serve in the IDF. Analysing the influence of military service in Israel raises questions about the impact of this service on the 'Defence Belief', or the 'Siege Mentality'. It is logical to presume that if one does military service, especially during periods of war, one will be discharged from army duty with the conviction that Israel is indeed under a great threat. This process could be a major contribution to the traditional 'survival' myth.

On the other hand, an insight into what happens during military service reveals that the IDF has a major influence on soldier's beliefs. Ex-IDF commanders and sociologists claim that the military service could be a turning point in terms of the ethos, and could lead to the development of a moderate point of view when it comes to security threats.

\section{ISRAEL'S SIEGE MENTALITY}

The decision to establish the IDF as a 'citizen-soldier military' originally arose from an ethnic-biblical context. The theme of external threat was char-

\footnotetext{
1 Yair (2011): 57-85.

${ }^{2}$ Lewin (2013): 15-35.

${ }^{3}$ Ben-Eliezer, Al-Haj (2006): 5-25.
} 
acterized as a feature of inter-generational continuity, whereby the Jewish people have adopted the characteristics of survival and victimization from the beginning of history. ${ }^{4}$ These beliefs were implemented in the Israeli culture and became myths of a religious-metaphysical nature. Hence, the image of the Israeli citizen holding a weapon was considered natural for the founders of the Jewish state.

At the end of Israel's Independence War (1948) the first Prime Minister, David Ben-Gurion, described the geo-strategic challenge:

We live in one of the most unstable periods in history [...] no country has yet recognized our borders, which are narrower in fact than in practice, based on the UN decision. The instability does not relate only to borders - there is no stable regime in the neighboring countries everything is shocked and unstable $\left[\ldots . . .{ }^{5}\right.$

The size of the State of Israel in the years of its inception affected the concept of threat in society: the concept of 'war on our soil' had a positive effect on the motivation to enlist since the short distance between front and hinterland was a psychological motive. ${ }^{6}$ Even during the 1960 s, the sense of existential threat was the basis for readiness to enlist including the return of past migrants in times of emergency. ${ }^{7}$ In his book Ethos Clash in Israeli Society, the researcher Eyal Lewin describes the characteristics of a 'Siege Mentality':

1. The state of Israel is a vital condition for the survival of Jews.

2. There will always be a war for survival.

3 . The only way to survive here is to win wars.

4. Only a great army will give us salvation. ${ }^{8}$

Lewin claims that these characteristics defines citizens who went through military service. Elran, another researcher, claimed that military service in Israel has significant influence on 'Siege Mentality'. Hence, the 'Defence Belief' is a never-ending developing spiral that defines Arabs as demons, increasing hatred, and fostering Islamophobia in the Israel Society. Lewin concludes that this sociological process defines a republican ethos, which clashes with the liberal trend in the last decades. Lewin characterizes the liberal ethos in four main points:

1. We are no longer at war for survival.

2. Israel is a multi-cultural state.

3. We always have to navigate towards peace with our neighbours.

4. A Palestinian state is an essential necessity for Israel's stability. ${ }^{9}$

\footnotetext{
${ }^{4}$ Almog (2014).

${ }^{5}$ Ben-Gurion (1971).

${ }^{6}$ Zigdon (2008): 56-94.

7 Gal (1986): 110-137.

${ }^{8}$ Lewin (2013): 57-74.

${ }^{9}$ Lewin (2013).
} 


\section{ISRAEL'S DEFENCE ETHOS}

Analysis of the Israeli society leads to a salient insight: the existential security of this society has been and still is a cultural ethos which affects the concept of national identity. ${ }^{10}$ This need for reinforcing national identity out of a sense of danger and crisis also influenced David Ben-Gurion's decision, as Israel's first Prime Minister, to build the IDF as a 'citizen-solider military', since he viewed the army as a socialization mechanism for achieving a cultural ethos. ${ }^{11}$

Our security issues are different than those of any other people in the world [...] not only because we are few against many, but because we're not yet a nation and we have no country. A population that does not recognize each other's languages, are not versant in the national culture and knowledge of the country, are not bound by a common culture and a national vision, is not a people that can fight its enemies on a rainy day [...].

The IDF is one of the major forces formulating the image of the state and unifying the people [...] the army builds the people. It turns people who were humiliated and oppressed into people with self-recognition and trust in their power.

A study that has being conducted over the last 10 years, measuring $\mathrm{Y}$ generation population's social attitudes, found that most Israelis feel like fresh migrants under existential threat, despite the fact that 70 years have passed since the state achieved independence, and that the Second World War was 80 years ago. ${ }^{12}$ In Israeli society, the concepts 'with our back to the wall' and 'the whole world is against us' were adopted as part of the traditions and values implemented by the educational system. ${ }^{13}$ Even Israeli leaders use existential terminology periodically perpetuating the concept: 'it is a nation that shall dwell alone'. Hence, the sense of a security threat 'resides' permanently among Israelis and the motivation at the basis of the decision to enlist the army still relates to fighting wars for survival. ${ }^{14}$

These findings raise an important question: how is it still the case that in Israel, a stable nation, with a strong advanced army, one of the most growing economies in the world, an empire of technology; how is it possible that Israeli citizens still feel like migrants under existential threat? Is the traditional survival myth stronger than what has been the actual, on-going reality for decades?

\section{IV. 'DEFENCE BELIEF' IN THE TWENTY-FIRST CENTURY}

Although Israel embarked on real peace arrangements that led to a reduction in the extent of the threats during the 1980 s and $1990 \mathrm{~s},{ }^{15}$ it was found

\footnotetext{
10 Shelah (2003): 23-41.

11 Ben-Gurion (1971).

12 Almog (2014): 337-370.

13 Yair (2011): 82-101.

14 Itsik (2013).

15 Tamari (2012): 49-66.
} 
that terror events since the beginning of the 2000s have led to a sense of 'fighting for home, from home', thus reinforcing the sense of threat in Israeli society. ${ }^{16}$ According to some sociologists, the Israeli 'siege mentality' has intensified since the establishment of the state. There are those who claim that the Israeli-Arab conflict became uncontrolled, developing a victimization and self-justification narrative, along with blind patriotism and glorification. ${ }^{17}$ In this way, the Israeli defence ethos includes even a sacrificial ritual that is reflected in the high motivation to enlist in elite units at the IDF. ${ }^{18}$

Other researchers claim that the service in the IDF intensifies a discourse about the contribution to the society - in the of most of Israelis way of view, warriors are far valuable to the society than other people. ${ }^{19}$ In Israel the ultimately contribution, even nowadays, is to join the army as a combat soldier. ${ }^{20}$ In that way, the military service embodies society's values.

A recent study on women's child expectations with regard to children in Israel made a dramatic discovery - nowadays, even when planning a family, the Jewish women in Israel think about the possibility that one of their children will die in a war as a soldier. ${ }^{21}$ As a consequence, the Jewish family in Israel is larger than the average in the Western world. Actually, Israeli Women see their children as future warriors; this could prove that there really is a deep cultural defence ethos.

Furthermore, army duty, including reserve and compulsory service, may be a significant factor in the inter-generational transference of the defence ethos. ${ }^{22}$ Studies examining the effect of army duty on the family found that among the families of those who serve in the army there is a tendency to adopt a set of military values. ${ }^{23}$

The concept of security threat in Israel is based on a number of elements which explain the extreme risk the population faces in times of emergency: ${ }^{24}$

- in the geographical context - a narrow country, the majority of the population residing on the coastal plane;

- in the geo-strategic context - a risk of invasion from Arab countries, threats of missiles and rockets, terror acts;

- in the demographic context - the challenge posed by the Israeli Arabs, as a threat of subversion.

Some claim that the reality of the peace arrangements that Israel has lived in since the 1980 s has reduced the existential fear; ${ }^{25}$ others maintain that since the 2000s there has been a change in the concept of threat among Israeli citizens. This is due to the second Palestinian uprising ('Intifada') in

\footnotetext{
16 Zigdon (2008): 103-138.

17 Bar-Tal (1997): 55-80.

18 Gal (2000): 224-240.

19 Sasson-Levi (2011): 73-98.

20 Tishler, Hadad (2011).

21 Mann-Shalvi (2016): 63-127.

22 Moskos and Segal (2000): 20-48.

${ }^{23}$ Vest (2012): 602-627.

${ }^{24}$ Grinberg (2001): 98-145.

25 Tamari (2012): 143-177.
} 
2002, and the second Lebanon war in 2006. Even the former Defence Secretary, nowadays a candidate on behalf of the liberal party, announced that the State of Israel is still fighting for its independence. ${ }^{26}$ East:

In the past decade, there have been far-reaching changes in the Middle

- instability of the Arab regimes, and the rise of Islamic extremism;

- increased threats from state-sponsored organizations (Hezbollah, Hamas, and the extreme Jihad), increased threats for the hinterland, due to enemies being armed with missiles and rockets;

- the discussion of the Iranian nuclear project, accompanied by declarations of the Iranian leaders on the need to 'annihilate' Israel.

Moreover, during the past few years the IDF has recruited reserve forces and was called to act with greater frequency than during the 1980s and 1990s. Some claim that this trend has led to an increased sense of threat among many in society. ${ }^{27}$ The sensation that war may break at any moment characterizes many of those serving in the IDF, hence it is natural to presume that there is a rise in the sense of existential threat.

\section{Graph 1}

Military average reserve days per soldier in the years 2007-2012

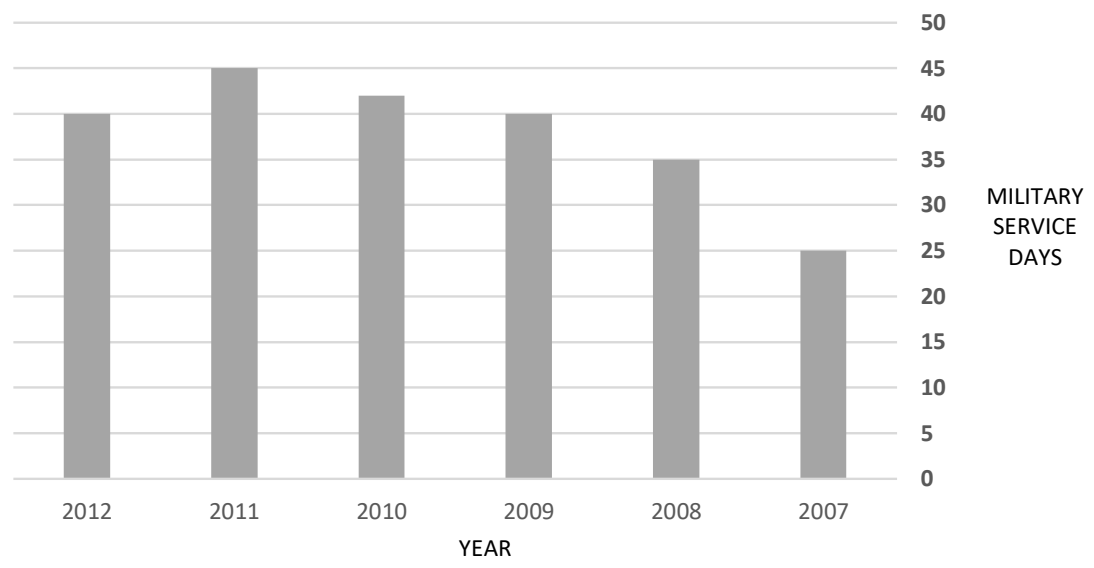

Source: IDF Human Resources (2013).

\section{MILITARY SERVICE AS A POINT OF DILEMMA}

There are opposing claims relating to the effect of the nature of army duty on the individual: on the one hand, it is claimed that the emotional experience during war may be traumatic, where the army is a 'republican agent' with lots

26 Yaalon (2008): 207-223.

27 Itsik (2013). 
of influence in the defence ethos context. ${ }^{28}$ On the other hand, it is claimed that even in times of conflict, the service has a moderating effect. ${ }^{29}$ In addition, there are those who claim that the sense of frustration involved in coping with terror attacks, leads to the desire for revenge and attitudes that negates the humanity of the other side, and gives legitimacy for immoral behaviour. ${ }^{30}$

Others claim that the above phenomena does not result from the military service but from the general public mood, and that the army service is a moderating factor in these contexts. ${ }^{31}$ Elazar Stern, a retired general from IDF and also a member of parliament representing the liberal party a liberal party, describes the military service as a 'melting-pot' that encourages tolerance and respect towards other cultures.

\section{Graph 2}

The perceived 'threat level' among Israeli citizens

6 HIGH

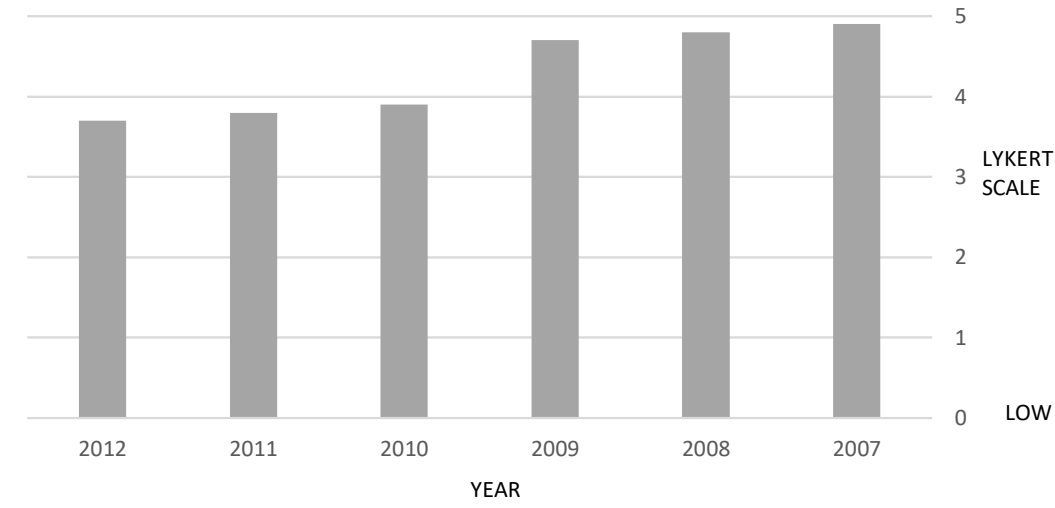

Source: Ben-Dor, Lewin, Kanetti (2013).

Amos Harel, a journalist that accompanied an IDF unit for two years, describes that during military service meeting 'real Arabs' gives the soldier an understanding that the conflict is not divided between 'black and white nor good and evil' in reality; and soldiers understand that most of the Arabs are not terrorists. ${ }^{32}$ Netta-Ly Colonimus and Daniel Bar-Tal, who studied an elite unit of the IDF for three years, describe a turning point that occurs in the final stage of the service: after understanding the real terrain some soldiers adopt a liberal ethos, based on the understanding that there has to be a peace pro-

\footnotetext{
28 Colonimus, Bar-Tal (2011).

${ }^{29}$ Harel (2013): 57-97.

30 Elran (2006).

31 Stern (2009): 137-155.

32 Harel (2013): 112-130.
} 
cess with the other side, who are also humans. ${ }^{33}$ In his book The Israeli Code, the sociologist Gad Yair claims that the meeting point between Arabs and Jews, despite the fact it occurs in combat terrains, there is a change of attitude that comes from the empathy towards the condition of the other side who lives in poverty and under an evil dictatorship, which suppress its citizens. ${ }^{34}$

A longitudinal study that has conducted about Israel's resilience since the year 2000, found that the 'threat level' perceived by citizens has been decreasing consistently since the year 2006. ${ }^{35}$ As was mentioned, in these particular years there was an increase in calling citizens to reserve duty (Graph 1).

The effect of the military service on the ethos raises an important question: could it be that only in battle situations do people understand the humanity of the other side, and could this be transferred ethically? This could be a paradox.

\section{DISCUSSION}

It is clear that the Israeli-Jewish ethos evolved from a brutal history of deportation, the Holocaust and wars for survival. Hence, it is logical that the average Israeli adopted the 'Defence Belief', and because of that his or her motivation to enlist in army are at a high level. consequences of the Defence Belief, on the other hand, are matter of debate.

A glance at recent Israeli politicians presents a clear picture - most of the retired Colonels and Generals from the IDF hold liberal opinions. Some say that retired IDF officers adopted a liberal ethos during service. ${ }^{36}$ This could proof that ethical turning point occurs during military service.

Most retired IDF officers who wrote books describe the other side - their Arab rivals - with a great deal of empathy. When there is an ongoing peace process, the IDF generals always lead the talks. This has been a consistent fact since Israel's first peace process with its greatest enemy, Egypt, in 1978. The reason is logical - they know one another from the field, they project fortitude, and they have the confidence necessary to make tough decisions. Moreover, in a society that lives under a 'Siege Mentality', army officers are considered honest and credible. In addition, the IDF is considered the most reliable institution in Israel. ${ }^{37}$ Beyond that, it almost became almost a tradition that IDF retired high-ranking officers are becoming members of parliament and government ministers, since they have gained a high level of trust. The military service of Israel's leader is an essential criterion in election debates, and it is repeated in every election to parliament.

\footnotetext{
33 Colonimus, Bar-Tal (2011).

${ }^{34}$ Yair (2011): 124-165.

35 Ben-Dor, Lewin (2017).

36 Hensbacher (2018).

${ }^{37}$ Harman et al. (2013).
} 


\section{Graph 3}

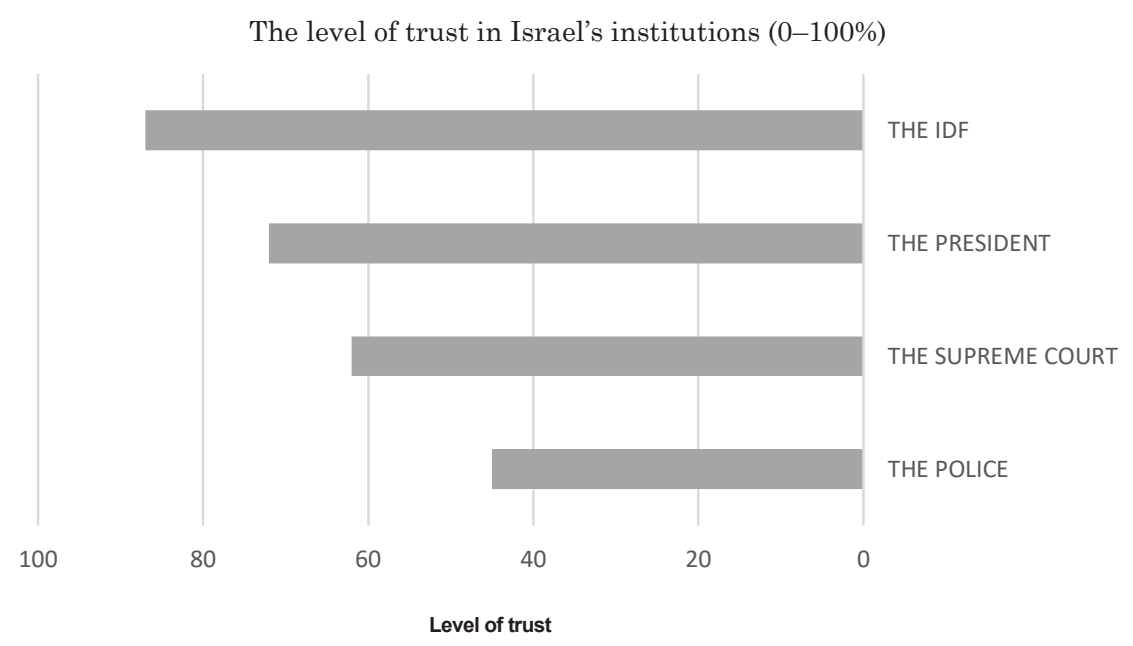

Source: Harman et al. (2013).

The IDF is known not just as a military organization that deals with security threats; it is also considered to be an educational institution. The first Prime Minister, Ben-Gurion, originally planned for the IDF to be a socialization platform. In addition to that, the basic stage of the officer's course in the IDF deals with education: in the IDF, a commander is considered first and most as an educator ${ }^{38}$. This also includes documented ethical orders, which explain how a soldier should act as a human being. Even in the second Palestinian upraising in 2002, which created thousands of suicide bombers who killed thousands of Jews in Israel's central cities, the IDF General commander's orders were: 'We have to win this war, and remain human-beings.' Every inquiry in the IDF deals with moral behaviour. Hence, it is logical that an institution that is considered as an educational place will change attitudes towards enemies, and after years of service can constitute an ethical turning point.

The IDF's moral code was written in the year 2001, after decades of wars, and it was implemented just in the last decade. This ethical document has major effects on operational and tactical decisions, and as has been shown, it is an educational element. In addition to the process of decreasing security threats in the soldier's eyes - the outcome is a change of attitude, which could affect the national ethos.

The researcher Dan Shiftan, in his article 'Strategic challenges for Israel towards is 60th Anniversary,' claimed that four generations after the establishment of the state of Israel, this society was adjusted to the special status of being the only non-Arab state in the Middle-East. ${ }^{39}$ According to

\footnotetext{
38 Stern (2009): 62-84.

39 Shiftan (2007).
} 
Shiftan, following peace agreements with its greatest enemies, Israel's citizens understood that their survival and prosperity are no longer under external threat.

\section{CONCLUSION}

The Israeli tradition is based on survival - that has been a historical fact for centuries. After the establishment of the Jewish state and the decision to construct a citizen-soldier army, also as a socialization platform and an educational mechanism, the reality and circumstances shaped the national ethos. After several peace agreements, the figure of the Israeli soldier has reformed. The conflict with the Arabs in the current combat terrain exposed soldiers to the suffering of the other side. The enemy that was a 'demon' became a human who also suffers. This trend, along with moral and ethical orders, developed a 'turning point' in security threats from a soldier's point of view.

After years of military service, the attitudes of soldiers change - they understand the complexity of the conflict with the Palestinians. The attitude change also influences also the security threat, as soldiers understand it; and hence this reduces the sense of threat. After being discharged from service, the attitude can evolve into a liberal ethos. These days, three retired IDF generals, all of them former chief of staff, lead a popular liberal party in the Israeli parliament. Their main slogan is: 'Peace is a thing that has to be considered. We have to revive hope in our state.'

There are researchers who claim that in recent years the primary purpose of military service in the IDF has become social activity, and that the defence mission has taken a secondary role. ${ }^{40}$ Others claim that the ID has become a platform for liberal values through its educational activity. ${ }^{41}$

In conclusion, Israel's 'Siege Mentality' security ethos has been eroded in the last decade by its main defence institution - the IDF. The question is what the consequences in the long run on Jewish tradition will be - will it still be based on survival?

Roen Itsik

Adam Mickiewicz University, Poznań

ronenits12@gmail.com

https://orcid.org/0000-0002-2452-9430

Almog, A. (2014). The Israeli Y generation. Haifa: The Samuel Neaman Institute for National Policy. Technion.

Bar-Tal, D., Staub, E. (1997). Patriotism in the Life of Individuals and Nations. Chicago: Nelson-Hall.

\footnotetext{
40 Tishler, Hadad (2011).
}

41 Barkai (2007). 
Barkai, Z. (2007). The Influence of Army Duty on Fashioning Political Attitudes, (Doctoral thesis). Haifa: Haifa University.

Ben Eliezer, U., Al-Haj, M. (2006). In the Name of Defense. Haifa: Haifa University.

Ben-Dor, G., Lewin, A., Kanetti, D. (2013). The Social Component of National Strength. Haifa: Center for National Security Studies, Haifa University.

Ben-Dor, G., Lewin. E. (2017). Israel's National Resilience. Haifa: Center for National Security Studies, Haifa University.

Ben-Gurion, D. (1971). Uniqueness and Mission - Issues of Israeli Defense. Tel-Aviv: Ma'arakhot.

Colonimus, N., Bar-Tal, D. (2011). The Concept of Conflict Ethos and Military Duty among Choice Units. Tel-Aviv: The Public Space, Tel-Aviv University.

Elran, M. (2006). National Strength - Effects of the 2nd Intifada on the Israeli Society. Tel-Aviv: Jaffe Center for Strategic Research.

Gal, R. (1986). A Portrait of the Israeli Soldier. Santa Barbara: Greenwood.

Gal, R. (2000). Still waiting in the wings, [in:] C. Moskos, J. Williams, D. Segal (eds.), The Postmodern Military. Oxford: Oxford University Press.

Grinberg, Y. (2001). A Fighting Nation. Beer-Sheva: Ben-Gurion University.

Harel, E. (2013). Every Hebrew Mother Should Know: The Image of the New IDF. Tel-Aviv: Kinneret, Zmora-Bitan, Dvir.

Harman, T., Heller, A., Atmor, N., Level, Y. (2013). The Israel Democracy Index. Tel-Aviv: Israel Institute of Democracy.

Hensbacher, Y. (2018). This is how IDF loose it's finest officers. MIDA 19.6.2018. <https://mida. org.i1/2018/06/19>.

IDF Human Resources (2013). The Motivation of Reserve Soldiers. IDF Department of Behavioral Sciences.

Itsik, R. (2013). Reserve Army Duty in Israel in View of Individualism (Thesis). Haifa: Haifa University.

Lewin E. (2013). Ethos clash, [in:] Israeli Society. London: Lexington.

Mann-Shalvi. H. (2016). From Ultra-Sound to the Army. Tel-Aviv: Wrestling.

Moskos, Ch.C., Williams, J.A., Segal, D. (2000). The Postmodern Military. Oxford: Oxford University Press.

Sasson-Levi, A. (2011). Women in a Professional Army: The Gender Implications of Moving towards a Professional Army in Israel. Tel-Aiviv: The Public Space, Tel-Aviv University.

Shelah, O. (2003). The Tray and the Silver: Why Do We Need a Revolution in the IDF. Tel-Aviv: Or-Yehuda, Kinneret, Zmora-Bitan, Modeen.

Shiftan, D. (2007). Strategic challenges for Israel towards its 60th anniversary, [in:] The Reader for the Course: Israel's National Security. Tel-Aviv. <https://www.ynet.co.il/articles/ 0,7340,L-3391224,00.html>.

Stern, A. (2009). The Beret Trek: Navigation at Eye Level. Tel-Aviv: Miskal.

Tamari, D. (2012). The Armed Nation. Tel-Aviv: Ma'arakhot.

Tishler, A., Hadad, S. (2011). Compulsory Army Service Versus a Professional Army - The Effect of the Manner of Recruitment on Israel's Military Strength. Caesarea: Caesarea Forum.

Vest, B.M. (2012). Citizen soldier or citizen-soldier - negotiating identity in the U.S National Guard. Armed Forces and Society 39(4): 602-627. doi:10.1177/0095327X12457725

Yaalon, M. (2008). A Long-short Way. Tel-Aviv: Miskal.

Yair, G. (2011). The Code of Israelism: The Ten Commandments of the Years 2000. Jerusalem: Keter.

Zigdon, Y. (2008). Deliberation in the Theory of Establishing Power. Tel-Aviv: Ma'arakhot. 


\section{ISRAEL'S DEFENCE ETHOS: MILITARY SERVICE AS A TURNING POINT}

S u m m a r y

Jewish culture deals a lot with survival stories - most of them became myths, especially since the establishment of the state of Israel. The Jewish 'survival ethos' is assimilated in Israel mostly by customs, traditions, and education. Above all, it has been claimed that military service in the Israel Defence Forces (IDF) is the most significant institution that empowers the survival ethos. As a result, it is assumed that those who serve in the IDF are characterized by hatred towards Arabs, and by being extreme nationalists. This claim is examined in the current article, which analyses the level of the sense of security threat among Israelis during the last decade, draws on data on military service and levels of trust in Israeli government institutions, and reveals an essential finding: Israeli's survival ethos is being eroded among IDF soldiers. This finding, followed by the fact that the leaders of the liberal party in the Israeli parliament are former military generals, indicates that military service in Israel does not empower extreme nationalism; on the contrary, service in the IDF has become a moderating social mechanism.

Keywords: defence ethos; security threat; citizen-solider military; terror; socialization 
